\title{
Taxonomic composition and abundance of zooplankton Copepoda in the coastal waters of Bintulu, Sarawak, Malaysia
}

\begin{abstract}
The abundance and composition of copepod was carried out in the coastal waters of Bintulu, Sarawak, Malaysia on March 2005. Samples were collected using conical plankton net with the mesh size of $153 \mu \mathrm{m}$. Copepod identified comprised of four orders namely, Calanoida, Cyclopoida, Harpacticoida and Poecilostomatoida. A total of 49 species belonging to 26 genera were identified. Nine most abundant species were Paracalanus crassirostris, Paracalanus elegans, Temora stylifera, Temora turbinata, Oncaea venusta, Corycaeus andrewsi, Corycaeus subtilis, Paracalanus parvus and Paracalanus denudatus. The first four species mentioned were the most abundant species and they accounted for over $50 \%$ of the total numbers of identified copepods. Copepod species which were rare and low in abundance included Delius nudus, Acrocalanus gracilis, Tortanus forcipatus, Centropages orsini, Corycaeus dahlia, Copilia mirabilis, Labidocera minuta, Microstetella rosea and Cosmocalanus darwini. Cosmocalanus darwini is new record to Malaysian waters. Species richness and diversity tends to increase towards the offshore while abundance increased towards the inshore stations.
\end{abstract}

Keyword: Coastal; Copepoda; Inshore; Malaysia; Offshore; Tropical; Zooplankton 